\title{
On-line early warning system for evacuation of socially vulnerable population during flooding
}

\author{
D. Mioc ${ }^{1}$, K. K. Moreiri ${ }^{2}$, J. N. Nkhwanana ${ }^{2}$, F. Anton ${ }^{1}$, \\ B. Nikerson ${ }^{3}$, E. McGillivray ${ }^{4}$, A. Morton ${ }^{4} \&$ P. Tang ${ }^{5}$ \\ ${ }^{1}$ National Space Institute, Technical University of Denmark, Denmark \\ ${ }^{2}$ Department of Geodesy and Geomatics Engineering, \\ University of New Brunswick, Canada \\ ${ }^{3}$ Faculty of Computer Science, University of New Brunswick, Canada \\ ${ }^{4}$ New Brunswick Emergency Measures Organization, Canada \\ ${ }^{5}$ New Brunswick Department of Environment, Canada
}

\begin{abstract}
Natural disasters normally find people unprepared and emergency planners are faced with a big task of evacuating people. The response time needed to evacuate people, especially those that are socially vulnerable is very important in saving lives. There exist a number of important factors when planning for an evacuation, e.g. the number of people to be evacuated, time available for the evacuations, the distance to travel and also the available routes for evacuation. The recent flooding in Fredericton has identified that the socially vulnerable population require more resources and emergency planning than the evacuation of the rest of population. The socially vulnerable population needs to be identified before the disaster occurs and their special needs need to be documented. The provisions of medicaments, special food and any additional resources have to be planned and prepared in advance. This paper presents the approach to identify, map and assist the evacuation of the population that is socially vulnerable during floodings in Fredericton while taking care of their special needs. The main result of our research is a web based GIS system that provides appropriate information to the relevant authorities and general public in a timely manner and easy to understand.

Keywords: flooding, evacuation, early warning system, vulnerable population.
\end{abstract}




\section{Introduction}

The main goal of our research is to create a web based Geographic Information Systems (GIS) application, which would help people living in flood plains, who may at one point be vulnerable due to their proximity to the river and the amplitude of the flooding. There are many factors that may lead to floods, and people living in flood plains are most likely to be affected. A flood plain is whereby a flat or gently sloping land adjacent to a stream, during high stream flow conditions, caused by excessive rainfall or snowmelt or a combination of the two, becomes inundated by water [1]. A large number of people in the Fredericton area reside along the Saint John River and its tributaries. We wanted to create a web based GIS application [2] that would provide timely flood information to emergency managers and general population, and the main functionalities of this application are to help identify people within certain distances within the floodplain, that may be affected by a particular flood. Web based GIS [3] is a methodology of building distributed GIS applications on the internet [4]. Web GIS offers the possibility of querying on a website that can help to identify the properties and the people who might be affected by the floods and who may then be contacted to have ample evacuation time.

Natural disasters normally find people unprepared and emergency planners are faced with a big task of evacuating people. This paper investigates how mapping of social vulnerable population can assist emergency planners in successful evacuation and allocation of resources. According to Hansjurgens [5],

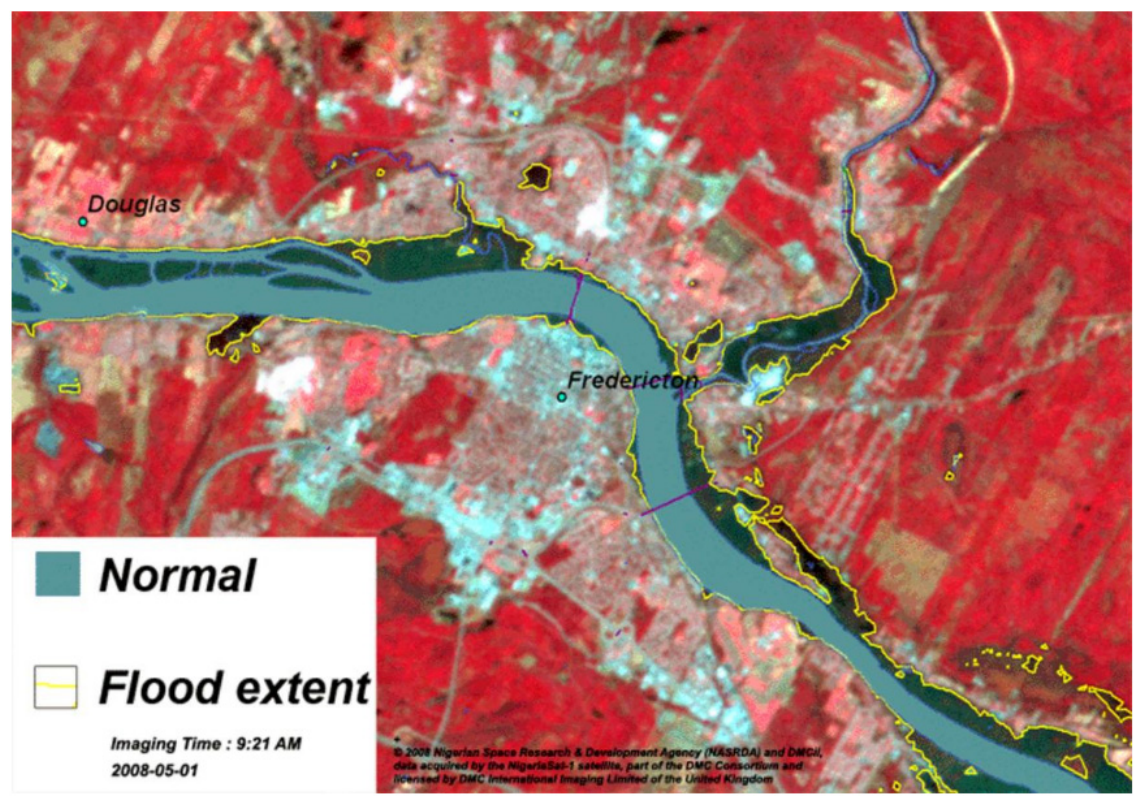

Figure 1: $\quad$ Satellite image of the study area taken during the flood in 2008. 
social vulnerability refers to the characteristics of a person or group and their situation that influence their capacity to anticipate, cope with, resist or recover from the impact of a hazard. He also argues that people/societies may be vulnerable to floods in terms of being less likely to be aware of flood risk, secondly, being less able to cope with it and respond to the threat, and thirdly, being less able to recover afterwards. This project investigates the vulnerability and the results maybe used to help in evacuation and recovery.

Flooding is common in Fredericton and the 1973 flood (see Figure 1) was considered to be the worst according to the officials of City of Fredericton [6], and recently in $2008 \mathrm{CBC}$ News [7] reported that about 40 streets were expected to be closed with water rising to levels above the 1973 flood. The same report mentions that 1300 homes would be affected in the process.

This paper also proposes that the mapping of this vulnerability should be web based [8]. This will allow emergency people to be able to access the information from the evacuation areas without having to rely on the GIS data sitting back at their offices. Watson [9] argues that it is important to get maps instantly with every team member. He also refers to the new technology that bridges the gap between a geospatial expert and a non-expert.

Usually, evacuation planning takes into account the following information:

- Characteristics of the hazard e.g. speed, duration, impact;

- Number of people to be evacuated;

- Time available;

- Distance to travel to ensure safety;

- Evacuation routes.

The evacuation process during flooding also requires information on accessible roads.

The vulnerability map will also show the location of temporary shelters to accommodate the population. It will also show the location of hospitals such that the emergency planners can easily locate the nearest hospital to the evacuation area when and if required.

\section{Study area}

It has been identified that more than $58 \%$ of the incorporated municipalities in the region of New Brunswick, reside within the Saint John River System [10]. The reason being that the waterways, during early settlement years, served not only as a source of major transportation for the early settlers, it also served as a source of livelihood for them as well. As the New Brunswick communities grew, so did the occupation of flood plains to the point where substantial damages, human sufferings and indeed, loss of lives occurred during major floods [1]. Furthermore, a publication by Jeanne Andrews [11] on floodings, highlighted the fact that flooding in Canada was a common phenomenon, resulting from an increase in stream flow beyond the point where the normal stream channel could contain the water. However, in most cases flood prone areas are often very attractive to the developer. 


\section{Prototype application design and implementation}

The main goal of our research was to create of a web based GIS system which could provide appropriate information to the relevant authorities in a timely manner and easy to understand. Relevant authorities in this case may include flood managers, flood warning practitioners, professional partners and emergency services to those affected [12]. Furthermore, we wanted the flood warnings available online and readily accessible to a broad audience to increase the level and quality of services provided [13].

The easy to use interface (see Figure 2) should also allow non-GIS experts to be in a position to interactively view and explore, as well as query the database, to select different data variables and to view maps at several levels of detail. We used ArcIMS to develop the web based GIS system [2]. When creating this website, it was taken into consideration that the provision of a map based information system in an easily accessible manner presents many challenges and as such, most search results displayed on the map would also be accompanied by textual sections below the map.

Our other objectives included:

- To assist flood warning practitioners as well as the general public to be in a position to query the website for flood evacuation routes, as such the website would allow them to identify evacuation routes as well as to have an idea of the water levels on flooded roads (see Figure 2).

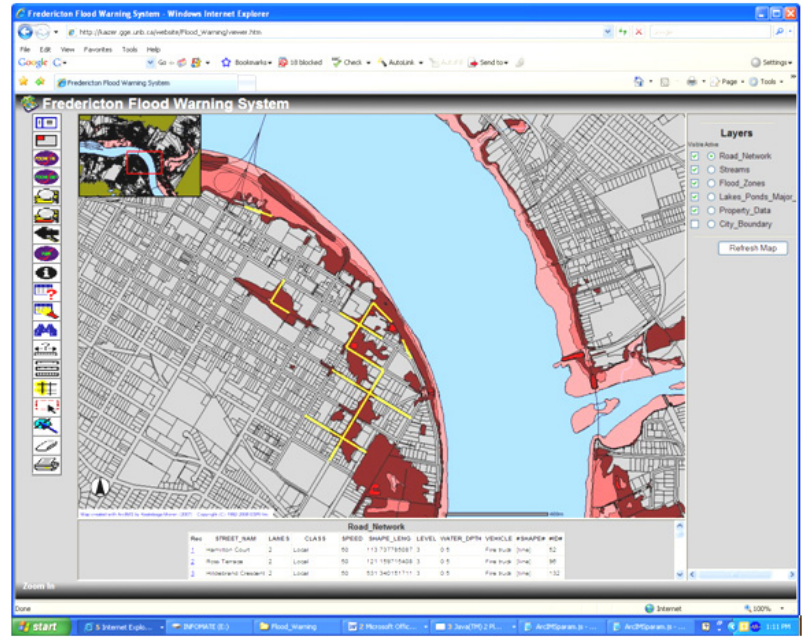

Figure 2: $\quad$ Output of a manually entered query.

- Design floods have also been utilised, for the system to have the capability of producing property data of properties that may be affected by a particular design flood. The design floods used are of 1 in 20 year 
flood, that is a flood having a return period of 20 years on average or having a $0.05 \%$ chance of occurring in a given year. Other design floods are 1 in 100 year and 1 in 200 year floods. These are intersected with the land use classification layer that includes industrial areas, offices, parks, shopping areas and residential blocks of people residing within the flood plain.

- This can be very helpful to flood practitioners to have an idea of the properties likely to be affected by such a flood (see Figure 4). Furthermore, city planners may also utilize the data when planning for future developments on flood prone areas to have an idea on the extent of the flood coverage of a possible maximal flood (shown on Figure 1).

Areas highlighted in yellow show the properties likely to be affected by a water level of three, which is up to 0.5 meters. In total, 243 properties would be affected by this water level rise (shown in Figure 3 and in Table 1 below):

Table 1: $\quad$ Identified property data.

\begin{tabular}{|c|c|c|c|c|c|c|c|c|c|c|}
\hline \multicolumn{3}{|c|}{ 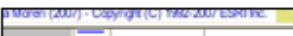 } & \multicolumn{6}{|c|}{ 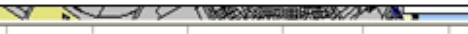 } & 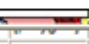 & \multirow{2}{*}{$\begin{array}{l}\text { मूरामा } \\
17486\end{array}$} \\
\hline 240 & 2487100.8 & 7441993.85 & 01413871 & 100 & 1973 & 3 & 0 & 2 & [polygon] & \\
\hline 241 & 2487144.05 & 7441996.15 & 01413384 & 100 & 1973 & 3 & 0 & 2 & [polygon] & 17504 \\
\hline 242 & 2487170.95 & 7442030.8 & 01415140 & 0 & 1973 & 3 & 0 & 2 & [polygon] & 17618 \\
\hline 243 & 2486935.05 & 7441933.5 & 75237180 & 100 & 1973 & 3 & 20 & 2 & [polygon] & 17787 \\
\hline & \multicolumn{10}{|c|}{ Previous 25 Records Zoom to these records } \\
\hline
\end{tabular}

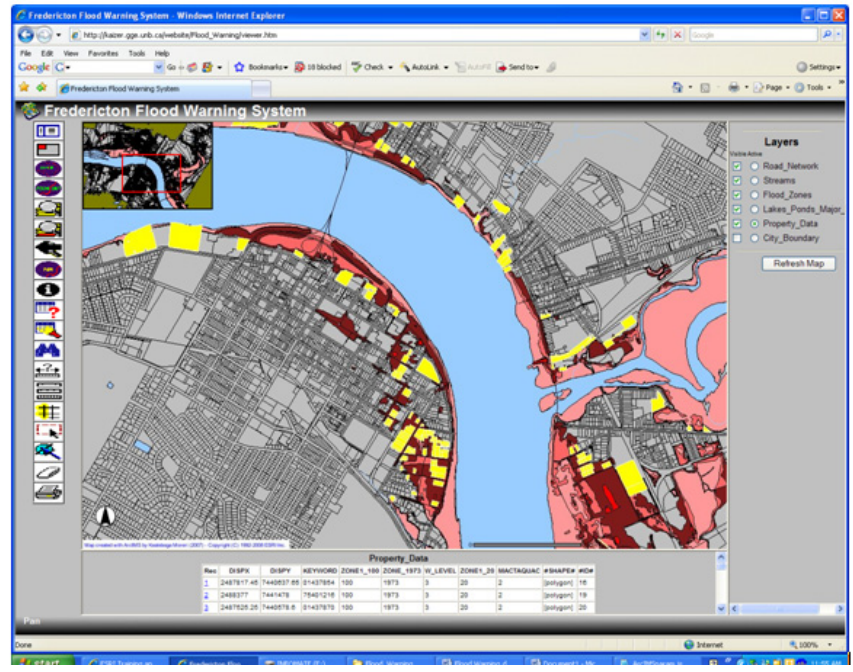

Figure 3: Properties affected by a particular flood water depth. (See online for a color version of this figure.) 


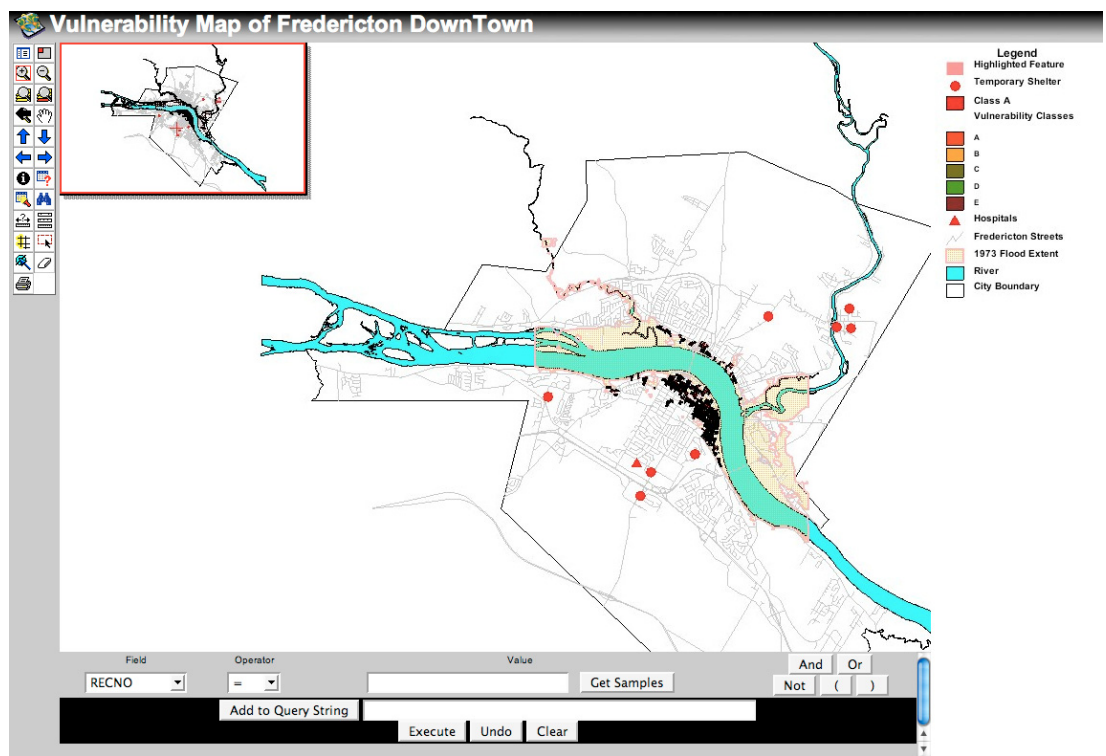

Figure 4: Web GIS application for mapping the socially vulnerable population during flooding.

\section{Mapping of social vulnerability}

Now we will present the mapping of the social vulnerability of each parcel that was affected by the 1973 flood. The 1973 flood extent was chosen because it was one of the worst floods in recent times in Fredericton and also because the data was readily available.

The mapping of social vulnerability was first introduced by [14]. There exists some calculation for social vulnerability, but they have all looked at blocks of population and not necessarily at each parcel [14, 15]. Chakraborty et al. [15] introduced a social vulnerability for Evacuation Assistance Index (SVEAI), which combines vulnerability factors.

This formula was used for the Hillsborough County, Florida and it works as follows:

1. For each variable $i$, determine the ratio of the variable in the block group to the total number of that variable in the county $(R i)$.

2. Compute a standardized Social Vulnerability for EvAcuation Index (SVEAI $i$ ) for variable $i$ using the maximum ratio value $R \max$ observed in the county.

$$
\operatorname{SVEAI} i=\frac{R i}{R \max }
$$


3. To combine multiple variables in the assessment of social vulnerability, calculate the arithmetic mean of the vulnerability indices by dividing the sum of index values of all variables by the number of variables $(n)$ considered.

$$
\mathrm{SVEAI}=\sum \frac{\mathrm{SVEAI} i}{\mathrm{~N}}
$$

This formula was adopted from Cutter et al. [6] who introduced a Social Vulnerability Index (SOVI). Cutter's formula is used to calculate social vulnerability for counties.

The above-mentioned approaches work with groups of people, but this paper attempts to demonstrate that mapping information at parcel level can be more useful to emergency planners during evacuation.

Cutter et al. [14] identified the following as indicators of Social Vulnerability:

- Age, gender, race, and socioeconomic status;

- Characteristics depicting special needs populations or those that lack the normal social safety nets necessary in disaster recovery;

- The quality of human settlements (housing type and construction, infrastructure, and lifelines) and the built environment.

The approach of this paper will not be based on a formula or any weighting system. The indicators will be mapped as they are or grouped according to level of assistance required.

Based on the past experience of emergency managers in New Brunswick, the following classification is used in our application:

The first class (see Table 2) will comprise households that have people requiring medical assistance or population aged over 85 years. Then, we will have another group of people above the age of 5 and who have disabilities.

The third class will be people with kids under the age of 5 and the fourth class will be families without cars or living in mobile homes.

The last class will be people who can evacuate with little or no outside help. The table below summarizes the classes we are using in our application.

Table 2: $\quad$ Vulnerability classes.

\begin{tabular}{|c|c|}
\hline Vulnerability Class & Description \\
\hline A & $\begin{array}{c}\text { Population requiring medical assistance or } \\
\text { Population above the age of 85 years }\end{array}$ \\
\hline B & Population with disabilities \\
\hline C & Kids under the age of 5 \\
\hline D & Families in mobile home or families without cars \\
\hline E & Population capable of self evacuation \\
\hline
\end{tabular}


Given this kind of information, emergency planners can know which households to assist first and also what resources to carry during the evacuation process. It is also acknowledged that a household can comprise one or more of the above classes, but in this case a household is given a class of the person/persons requiring the most assistance.

\section{The web GIS application for evacuation of socially vulnerable population}

For web based implementation of the early warning system for evacuation of socially vulnerable population we decided to use ESRI ArcIMS software.

ArcIMS offers two main templates, one based on HTML and another that runs through Java applets. The HTML template and the ArcGIS server have an advantage in that they do not require installation of Java on a client's computer to run. On the other hand a Java template offers an editing capability in the form of map notes that can be very useful for emergency planners.

Given the MapNotes functionality, users can create notes of their application and share with other users of the same Internet GIS application.

To give an example, each team can easily create a new point symbol for each household they have evacuated. This information can then be shared with other teams so that teams that have finished their work can know which households still require assistance. At the same time the progress can be centrally monitored to ensure that people are evacuated timely or if there is extra help required.

The ArcIMS HTML view was adopted for this paper. The application has eight datasets shown on Figure 5:

- Vulnerability classes;

- Class A (from vulnerability classes);

- Temporary shelter;

- Hospitals;

- 1973 Flood extent;

- St. Johns river;

- Fredericton streets;

- City boundary.

The database for Class A was created separately to show medical conditions of the people requiring assistance during evacuation. Given these extra details, the emergency planners can therefore select the appropriate shelters for the evacuated population using information from the shelters (see Table 3). The table below summarizes the queries available [8]. 


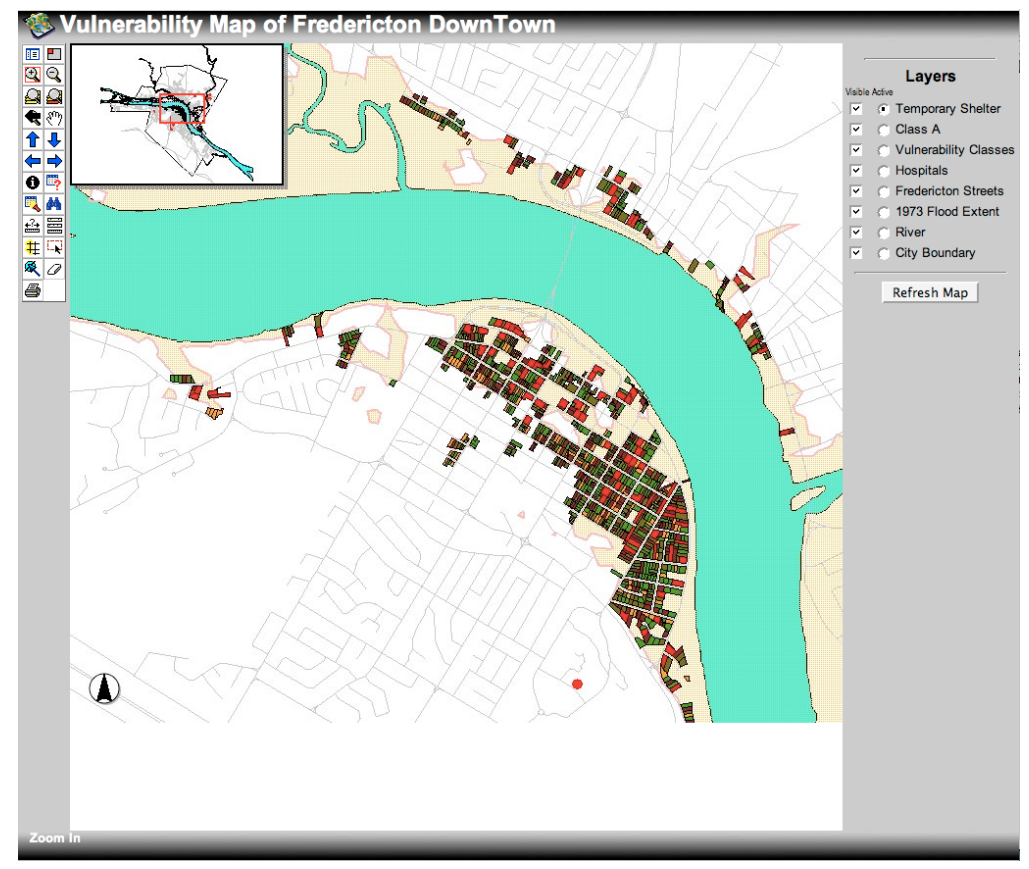

Figure 5: Data layers on the map available for the queries.

Table 3: $\quad$ Summary of the queries available within the application.

\begin{tabular}{|l|l|}
\hline Dataset & Queries available \\
\hline Vulnerability Classes & $\begin{array}{l}\text { Number of Residents, Vulnerability } \\
\text { Class }\end{array}$ \\
\hline Class A & $\begin{array}{l}\text { Number of Residents, Medical } \\
\text { Condition }\end{array}$ \\
\hline Temporary Shelter & $\begin{array}{l}\text { Shelter Name, Capacity, Available } \\
\text { support equipment }\end{array}$ \\
\hline Fredericton Streets & Street Name \\
\hline
\end{tabular}

In our application we provided sample values for each query for nonexperienced users (see Figure 6).

ArcIMS allows queries of one dataset at a time, i.e. a user cannot query two or more datasets at the same time. For example, a user can only query Vulnerability classes and it cannot combine the query with one from Temporary Shelters (shown in Figure 7). 


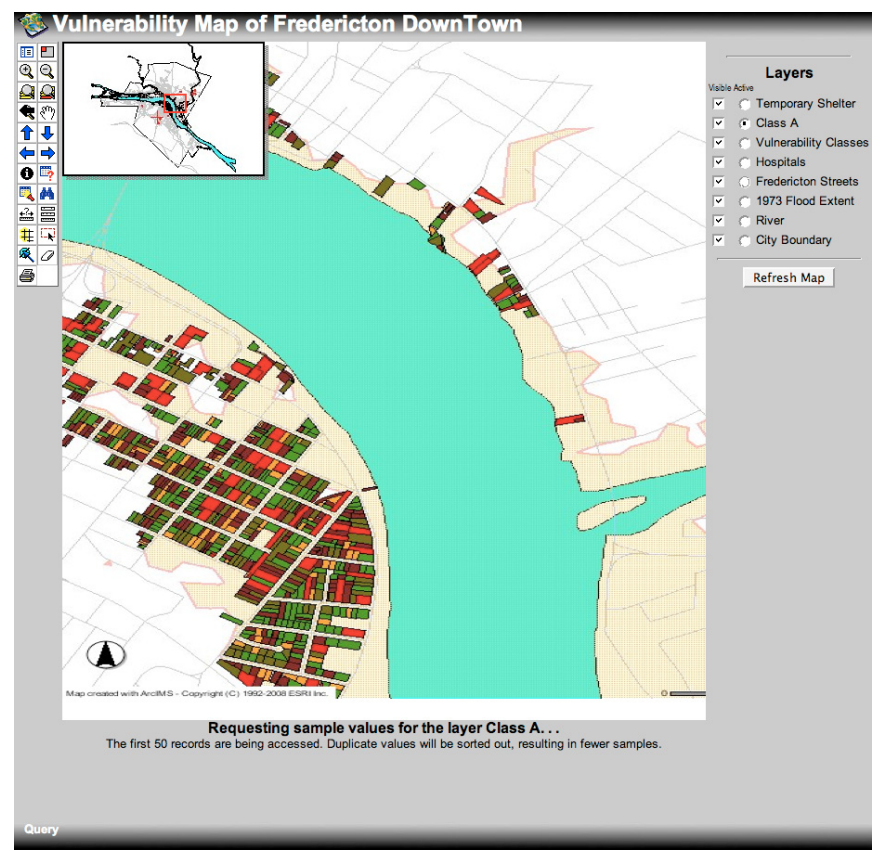

Figure 6: Query example for class A.

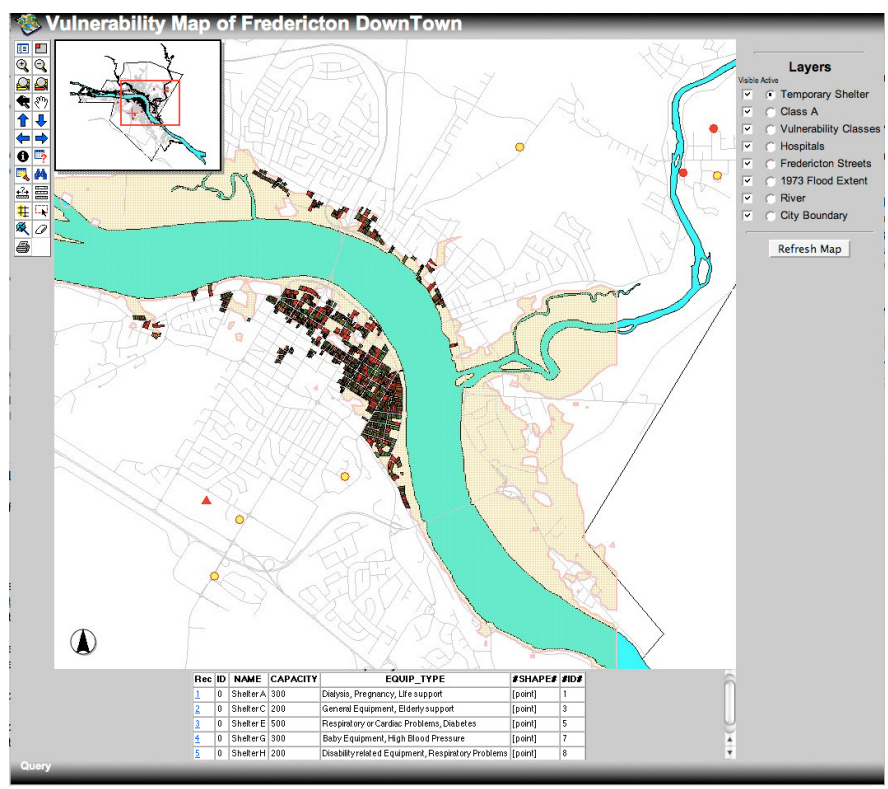

Figure 7: Query for the facilities available in temporary shelters. 


\section{Conclusions}

The results of this research provide a prototype of the web-based application for Fredericton's flood warning system, where accurate and timely warnings can be achieved, and thus maximizing the response time for flood plain residents and emergency managers and to provide a powerful planning tool for flood prone areas. Furthermore, proper evacuation routes can be planned well on time, when water depths on several streets likely to be affected by the floods are known. The idea was to bring the results that would show the inundation at a particular level, represented by a color code, for example having to represent the selections of a particular water level with a particular color for clear distinction.

The developed WebGIS application can assist flood warning practitioners as well as individual people to query the website, for flood evacuation routes; as such the website would allow them to identify evacuation routes as well as to have an idea of the water levels on flooded roads. The flood warnings application is available online and readily accessible to a broad audience to increase the level and quality of services provided.

Using the results of hydrological modelling the system has the capability of identifying the properties that may be affected by an upcoming flood. This can be very helpful to flood practitioners to have an idea of the properties likely to be affected by flooding.

Furthermore, the mapping of socially vulnerable population affected by the flood is presented. Population evacuation in times of disasters is a very important factor and mapping of socially vulnerable population in those areas could go a long way in helping emergency planners in their efforts to evacuate people. This mapping combined with physical hazards and other warning measures have important roles in saving lives and also helping people recover after disasters.

\section{Acknowledgements}

This project was financially supported, in part, by the NB Emergency Measures Organization and by the Canadian Department of Natural Resources Geoconnections program as well as by University of New Brunswick and New Brunswick Innovation Foundation (NBIF).

\section{References}

[1] Spear MacDonald and Associates Limited, Cumming - Cockburn and Associates, Canada, New Brunswick Program for a Hydrotechnical study of the Walker Brook Flood plain, Summary Report, 1983, revised in 1985.

[2] Moreri, K., Mioc, F. Anton, D, B. Nickerson, E. McGillivray, A. Morton, D. Fraser, P. Tang, 2008. Early warning and mapping for flood disasters, Joint ISCRAM-CHINA and Gi4DM Conference, Harbin, 2008, 6 pages.

[3] Zipf, A., and Leiner, R., Mobile Internet GIS based Flood Warning and Information Systems, 2nd Symposium on Location Based Services and TeleCartography, Vienna, Austria, 2004. 
[4] Shea, G. Y. K., A Web-Based Approach to the Integration of Diverse Data Structures for GIS, M. Eng. Thesis, The University of New South Wales, 2001.

[5] Hansjurgens, B., Megacities, Risk and Social Vulnerability, Helmholtz Association, Retrieved November 13, 2008 from http://www.ehs.unu.edu /file.php?id=334, 2007.

[6] City of Fredericton, Retrieved December 2, 2008 from http://www.fredericton.ca/en/publicsafety/2008April1FloodWatch.asp, 2008.

[7] Canadian Broadcasting Corporation, $C B C$ News, Retrieved online on December 2, 2008 from http://www.cbc.ca/canada/new-brunswick/story /2008/04/30/nb-flood.html, 2008.

[8] Nkhwanana Nyaladzani J., D. Mioc, 2009. Early warning system for evacuation of socially vulnerable population during flooding, Joint Symposium Cartography and Geoinformatics in Early Warning and Crises Management, Towards Better Solutions. January 19-22, 2009 in Prague, 6 pages.

[9] Watson, C., Using GIS Data for Emergency Preparedness and Response, Retrieved November 30, 2008 from www.geoplace.com, 2008.

[10] Department of the Environment, Water Resources Branch, Fredericton Planning Region Water Resources Review, Report I - 8001, 1980.

[11] Andrews, J. (Ed.), Flooding, Canada Water Book, Canada Communication Group, 1993.

[12] Butts, M.B. and Khatibi, R., Workpackage 7: Operational End-user Requirements - General Functionality deliverable 7.1-Part 1, (FLOODRELIEF project), http://projects.dhi.dk/floodrelief, 2003.

[13] Gibson R. and Erle S., Google Maps Hacks: Tips and Tools for Geographic Searching and Remixing, O'Reilly Media Inc., 2006.

[14] Cutter, S.L., Boruff, B.J., Shirley, W.N., Social Vulnerability to Environmental Hazards, Social Science Quarterly 84 (2), pp.242-261, 2003.

[15] Chakraborty J. et al., Population Evacuation: Assessing Spatial Variability in Geophysical Risk and Social Vulnerability to Natural Hazards, Natural Hazards Review, ASCE, 6(1), pp.23-33, 2005. 